\title{
Trial of labour after caesarean delivery
}

\author{
Elizabeth Miazga MD, Eliane M. Shore MD MSc
}

Cite as: CMAJ 2022 January 10;194:E13. doi: 10.1503/cmaj.211686

\section{1 \\ 2} Trial of labour after cesarean (TOLAC) is a safe alternative to repeat cesarean delivery ${ }^{1}$

Pregnant people who have had a previous cesarean delivery can have a TOLAC or an elective cesarean. For patients with high likelihood of vaginal birth after cesarean (VBAC), TOLAC is the recommended mode of delivery. ${ }^{2}$ A tool to calculate likelihood of VBAC is available (https://mfmunetwork. bsc.gwu.edu/web/mfmunetwork/vaginal-birth-after-cesarean-calculator). ${ }^{3}$ Three-quarters of people who attempt TOLAC will have a VBAC ${ }^{1}$ Vaginal birth after cesarean is more likely in patients with a previous vaginal delivery (83\%) or VBAC (94\%). ${ }^{1}$ In comparison, the probability of vaginal delivery in a primiparous term patient in Canada is $76 \% .{ }^{4}$ Induction of labour decreases likelihood of VBAC, but is safe with mechanical cervical ripening, oxytocin and amniotomy. ${ }^{2}$

\section{Uterine rupture is a rare complication of TOLAC ${ }^{1,2}$}

Uterine rupture at the site of the uterine scar complicates $0.47 \%$ of TOLAC attempts. ${ }^{1}$ Risk of rupture increases with 2 or more cesarean deliveries $(1.6 \%)$, less than 18 months between deliveries $(4.7 \%)$, or induction of labour (1.2\%).1,2

\section{Hospital-based care is required for TOLAC}

- Continuous fetal heart monitoring is required during active labour. The most common sign of uterine rupture is an abnormal fetal heart tracing, particularly complicated variable, late or prolonged decelerations. ${ }^{1,2}$ If uterine rupture is suspected, an emergency laparotomy and urgent delivery are required. Therefore, onsite surgical and anesthesia teams are needed to support TOLAC. ${ }^{2}$

\section{Patients should be counseled regarding their eligibility for TOLAC}

Early counselling about TOLAC and the recommended 18-month interdelivery interval after cesarean may increase its acceptance, leading to lower cesarean delivery rates. ${ }^{5}$ Absolute contraindications to TOLAC are previous or suspected inverted $\mathrm{T}$ or vertical uterine incision, previous uterine rupture or major uterine reconstruction, including myomectomy. ${ }^{2}$ If the previous uterine incision orientation is unknown, TOLAC is not contraindicated unless the cesarean was for a very preterm infant, as this increases the likelihood of vertical incision..$^{1,2}$

\section{References}

1. Guise JM, Denman MA, Emeis C, et al. Vaginal birth after cesarean: new insights on maternal and neonatal outcomes. Obstet Gynecol 2010;115:1267-78.

2. Dy J, DeMeester S, Lipworth H, et al. No. 382: Trial of labour after caesarean. J Obstet Gynaecol Can 2019;41:992-1011.

3. Chaillet N, Bujold E, Dubé E, et al. Validation of a prediction model for vaginal birth after caesarean. J Obstet Gynaecol Can 2013;35:119-24.

4. Gu J, Karmakar-Hore S, Hogan M-E, et al. Examining cesarean section rates in Canada using the modified Robson classification. J Obstet Gynaecol Can 2020;42:757-65.

5. Eden KB, Hashima JN, Osterweil P, et al. Childbirth preferences after cesarean birth: a review of the evidence. Birth 2004, 31:49-60.

Competing interests: Elizabeth Miazga reports receiving a University of Toronto Medical Humanities Grant. Eliane Shore reports receiving St. Michael's Hospital AFP Innovation Grants, a McArthur grant from the University of Toronto, and an Exploration Fund Grant from North York General Hospital. Dr. Shore also reports membership (unpaid) of the Canadian Society for Advanced Gynaecologic Excellence Board. No other competing interests were declared.

This article has been peer reviewed.

Affiliations: Department of Obstetrics and Gynecology, Unity Health - St. Michael's Hospital; Department of Obstetrics and Gynecology, University of Toronto, Toronto, Ont.

Content licence: This is an Open Access article dis tributed in accordance with the terms of the Creative Commons Attribution (CC BY-NC-ND 4.0) licence, which permits use, distribution and reproduction in any medium, provided that the original publication is properly cited, the use is noncommercial (i.e., research or educational use), and no modifications or adaptations are made. See: https://creativecommons. org/licenses/by-nc-nd/4.0/

Correspondence to: Elizabeth Miazga, Elizabeth.miazga@mail.utoronto.ca 